\title{
Thermal Stress Analysis of a Gas Turbine Casing Using F E A
}

\author{
C Rajesh Babu ${ }^{1}$ \\ Assistant professor ${ }^{l}$ Mechanical Engineering Department, GITAM School of Technology, GITAM UNIVERSITY, \\ Rudraram, HYDERABAD-502329, India. \\ crb.rajesh@gmail.com
}

\begin{abstract}
Gas Turbines are widely used in the industry today in the areas of power generation, aero engines, mechanical drives, marine applications, locomotive applications etc. With such wide range of applications, it is necessary to improve the designs on continual basis for increased efficiency, reliability, availability and cost reduction. All the original manufacturers in the world are spending the amounts of money on such new developments. Gas Turbine casings are generally of thin wall design to reduce thermal inertia to enable quick start up and shut-downs. While the aero engine casings are made of super alloy materials, land based engine casings are made of cast iron to reduce cost. In case of tip rubs (between blade tip and casing at high rotational speeds, which is very common in Gas Turbines), material erosion takes place in the casings. The eroded material comes out in the form of powder, in case of cast iron and hence does not cause damage to the subsequent sections. In the present case, Turbine casing has been analysed for temperature distribution first. There is hot ambient inside the casing and relatively cold ambient outside, because of which there is a temperature gradient. This condition is taken care in the analysis by defining convection boundary conditions both on inside and outside of the casing. The temperature output of the analysis is given as input to structural analysis along with pressure loads to get combined thermal and mechanical stresses. The outcome of the present work can be used for changing the operating conditions of the Gas Turbine to higher parameters or for resolving any machining deviations.
\end{abstract}

Keywords: Gas turbine Casing; ASTM A 395; Thermal Stresses; FE Analysis

\section{Introduction}

The gas turbine is a rotating internal combustion engine, which takes air from the atmosphere and compresses it to a higher pressure in an axial compressor (compressor section) and the compressed air flows into combustion chamber where fuel is admitted and ignited with the help of a spark plug. The products of combustion are used as a working fluid for developing power in the turbine section of the Gas Turbine. The thermodynamic cycle upon which a gas turbine works is called the Brayton Cycle. A schematic diagram of a single shaft, simple cycle gas turbine is shown in Fig. 1 Air enters the compressor at point 1 of the schematic at ambient conditions. The air is compressed to a higher pressure in the compressor. Upon leaving the compressor, the air enters the combustion system at point 2, where fuel is injected and combustion takes place. The combustion process occurs at essentially at constant pressure. The combustion system is designed to provide mixing, dilution and cooling. Thus, by the time the combustion mixture leaves the combustion system and enters the turbine at point 3 , it is at some mixed average temperature. In the turbine section of the Gas turbine, the energy of hot gases is converted into work. This conversion actually takes place in two steps. In the nozzle section of the turbine, the hot gases are expanded and thus a portion of the thermal energy is converted into kinetic energy. In the subsequent bucket section of the turbine, a portion of the kinetic energy is transferred to the rotating buckets and is converted to work. Fig. 2 shows Temperature-entropy (T-s) diagrams for the Brayton Cycle.

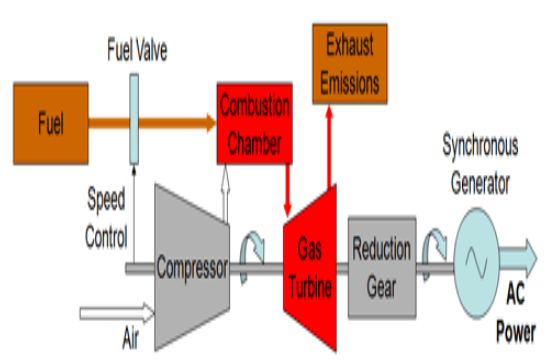

Fig 1. Gas turbine power plant (Source by: www.mpoweruk.com)

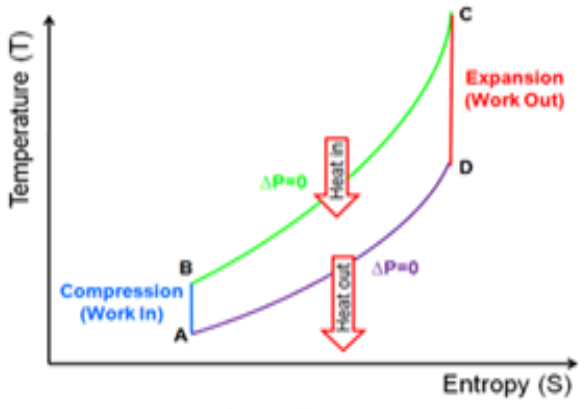

Fig 2. T-S Diagram of Brayton cycle (Source by: www.mpoweruk.com) 
In this project the material taken as ASTM A395.This specification covers standard requirements for ductile iron castings for pressure-retaining parts for use at elevated temperatures. Castings are classified by grades based on mechanical property requirements. These iron castings shall meet the specified values of tensile strength, yield strength, elongation and hardness. Chemical analysis shall be performed wherein the casting shall conform to the required chemical composition for carbon, silicon, and phosphorous. The material shall meet the required tensile properties, hardness, and microstructure. The iron casting shall undergo pressure test after machining. The thickness of any repaired section in relation to the size of the plug used shall be indicated. The minimum radius of repaired sections of cylinders or cones in relation to the size of plug used shall not exceed the prescribed limit. Other defective areas may also be repaired by plugging provided the minimum ligament between plugs in adjacent areas shall not be less than twice the distance from the nearest plug. Three Y-blocks shall be utilized as test coupons. The material shall undergo the following test methods: tension test, chemical analysis, yield strength test, and hardness test.

\section{Methodology}

The basic steps involved in solving CFD problem are as follows:

- Geometry Modelling.

- Grid generation.

- Specification of boundary Conditions.

- Selection of solver parameters and Convergence criteria

- Results and post processing

\section{Boundaryconditions}

Thermal analysis:

There is hot ambient inside the casing and relatively cold ambient outside, because of which there is a temperature gradient. This condition is taken care in the analysis by defining convection boundary conditions both on inside and outside of the casing.

Film coefficient on inner surface

Ambient temperature on inner surface

$=0.02 \mathrm{~W} / \mathrm{cm}^{2} /{ }^{\circ} \mathrm{C}$

Film coefficient on outer surface

$=356^{\circ} \mathrm{C}$

$=0.01 \mathrm{~W} / \mathrm{cm}^{2} /{ }^{\circ} \mathrm{C}$

Ambient temperature on outer surface

$=67{ }^{\circ} \mathrm{C}$

\section{Structural analysis:}

Symmetric boundary conditions are applied in structural analysis. Since any point on vertical cutting plane cannot move in horizontal direction, due symmetric conditions, this plane is defined with $\mathrm{Ux}=0$. Similarly the horizontal parting plane is defined with $\mathrm{Uy}=0$. The boundary conditions are shown in fig. A pressure load of 11 $\mathrm{Kg} / \mathrm{cm}^{2}$ is specified on inner surface of the casing, which is the maximum air pressure inside the turbine section at base load of the unit.

Material Properties:

The material of the casing is ASTM A 395. Following are the material properties.

Thermal:

Specific heat

Thermal conductivity

Density

\section{Structural:}

Young's modulus

Poison's ratio

Coefficient of thermal expansion

Yield stress of cast iron

$$
\begin{array}{r}
-480 \mathrm{~J} / \mathrm{kg} /{ }^{\circ} \mathrm{C} \\
-0.28 \mathrm{~W} / \mathrm{cm} /{ }^{\circ} \mathrm{C} \\
-0.0078 \mathrm{~kg} / \mathrm{cm}^{3}
\end{array}
$$

$$
\begin{gathered}
-2.1 \mathrm{E}+06 \mathrm{Kg} / \mathrm{cm}^{2} \\
-0.3 \\
-1.15 \mathrm{E}-05 /{ }^{\circ} \mathrm{C} \\
-2817 \mathrm{Kg} / \mathrm{cm}^{2}
\end{gathered}
$$




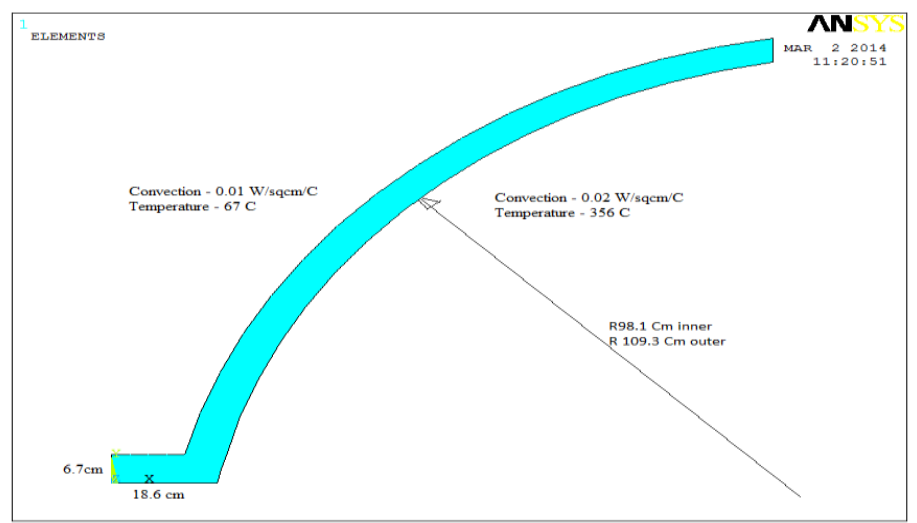

Fig .3 Cross section of the casing in FLUENT

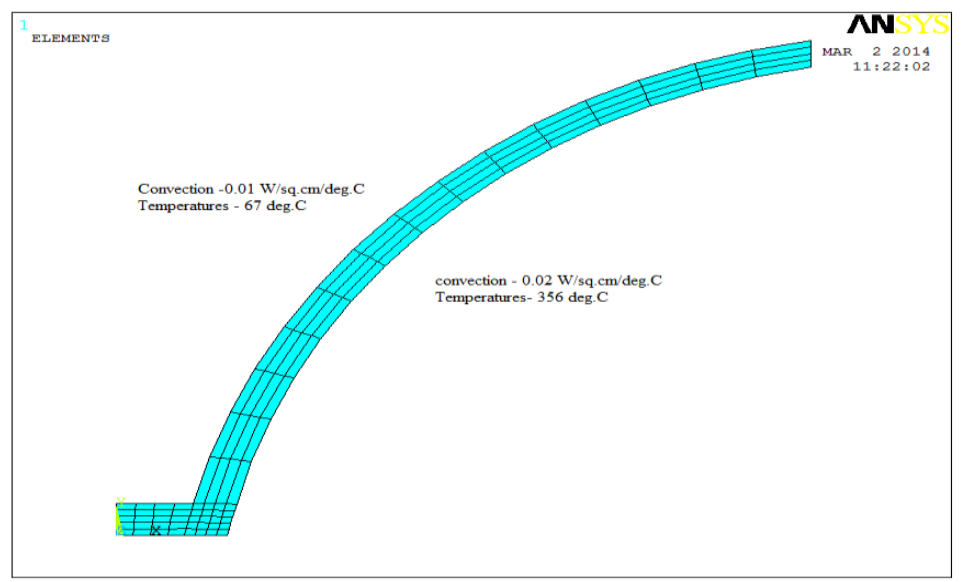

Fig 4. Mesh with thermal boundary conditions in FLUENT

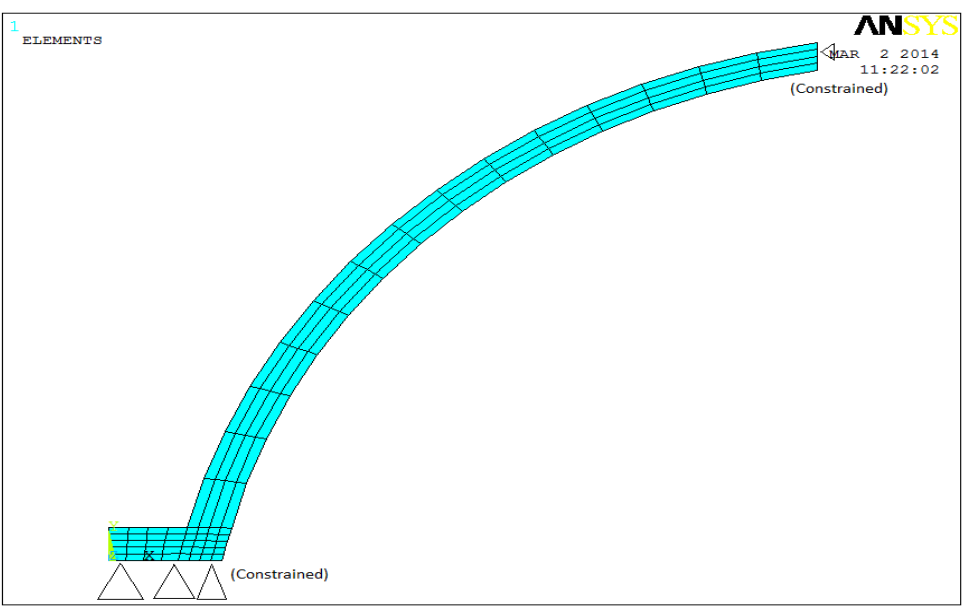

Fig. 5 Mesh with structural boundary conditions in FLUENT 


\section{Solutions}

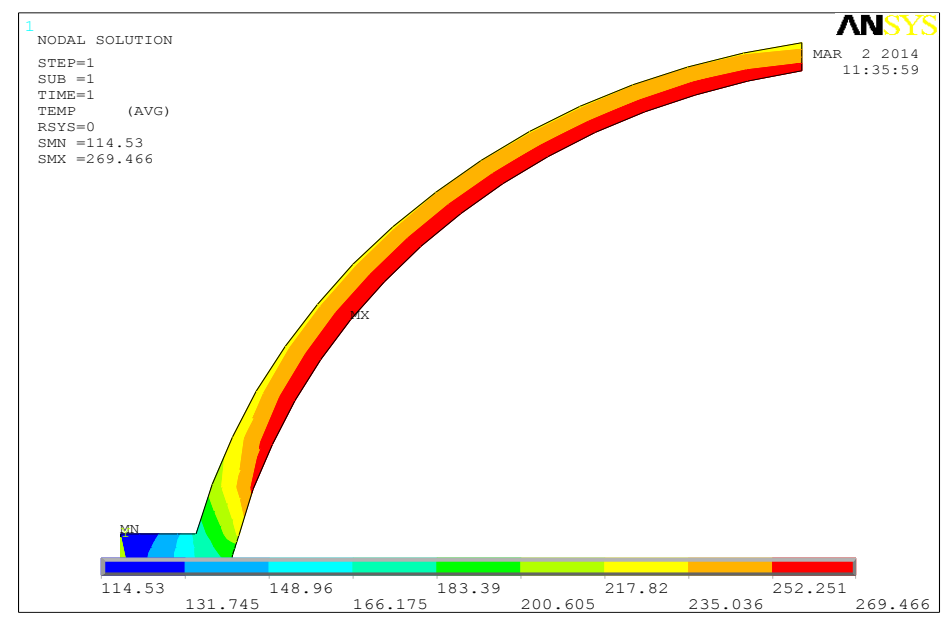

Fig. 6 Temperature distribution contours in FLUENT

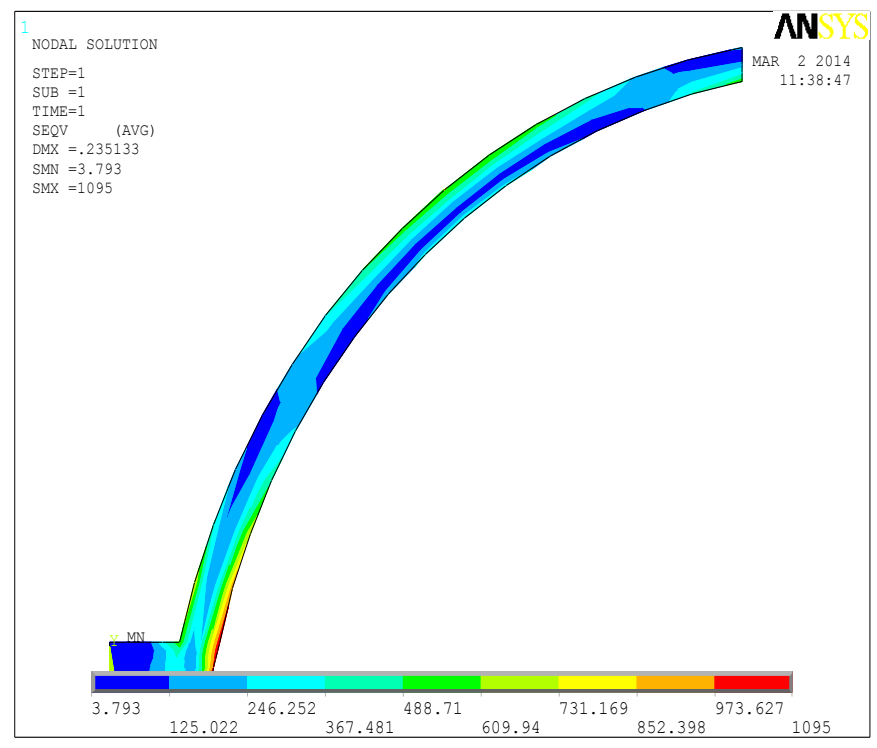

Fig 7. Von-mises stress (Pressure contours) - Only mechanical loads

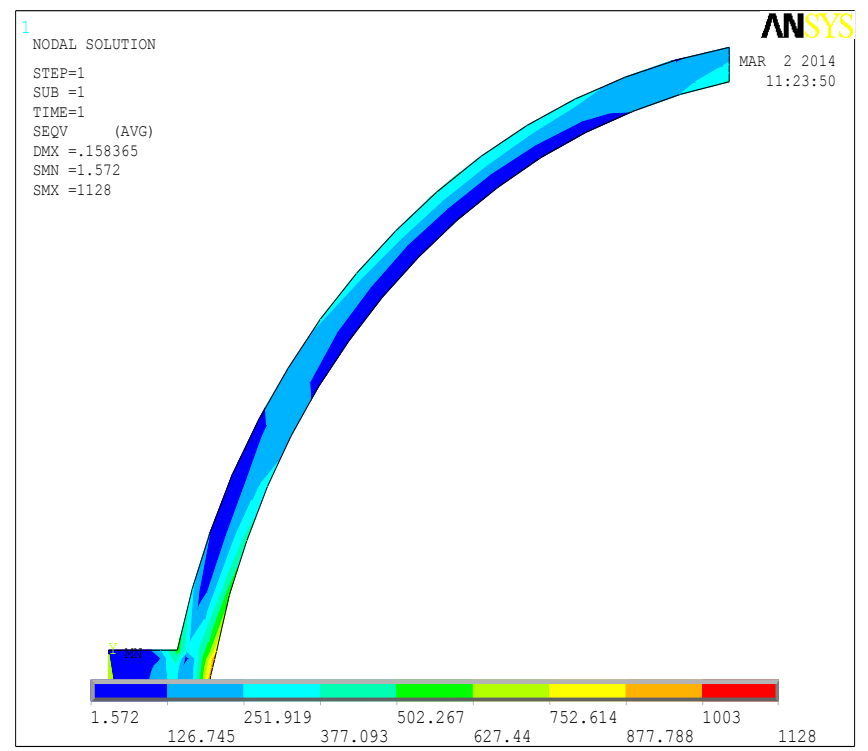

Fig. 8 Von-mises stress contours - Thermal and mechanical loads 


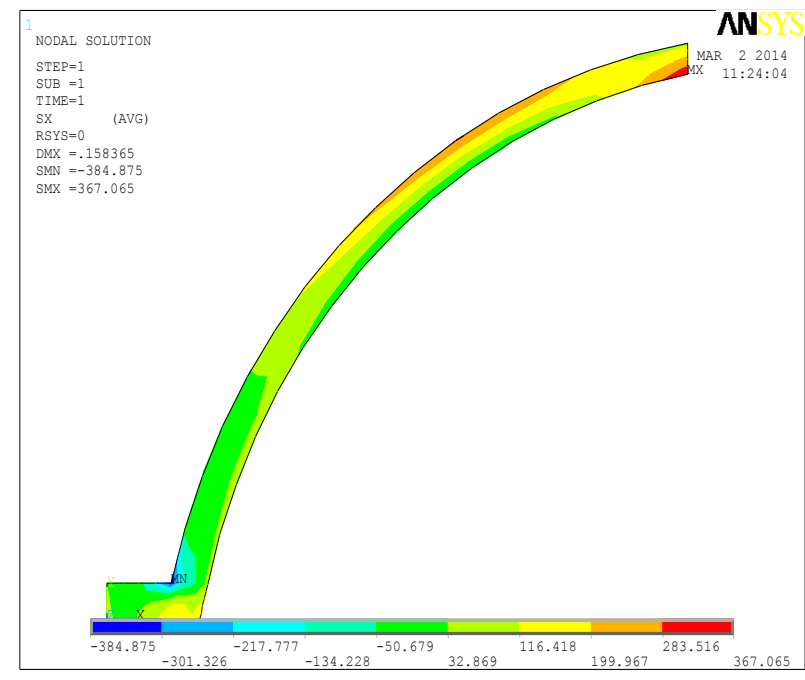

Fig. 9 Stress in X-direction Thermal and mechanical loads

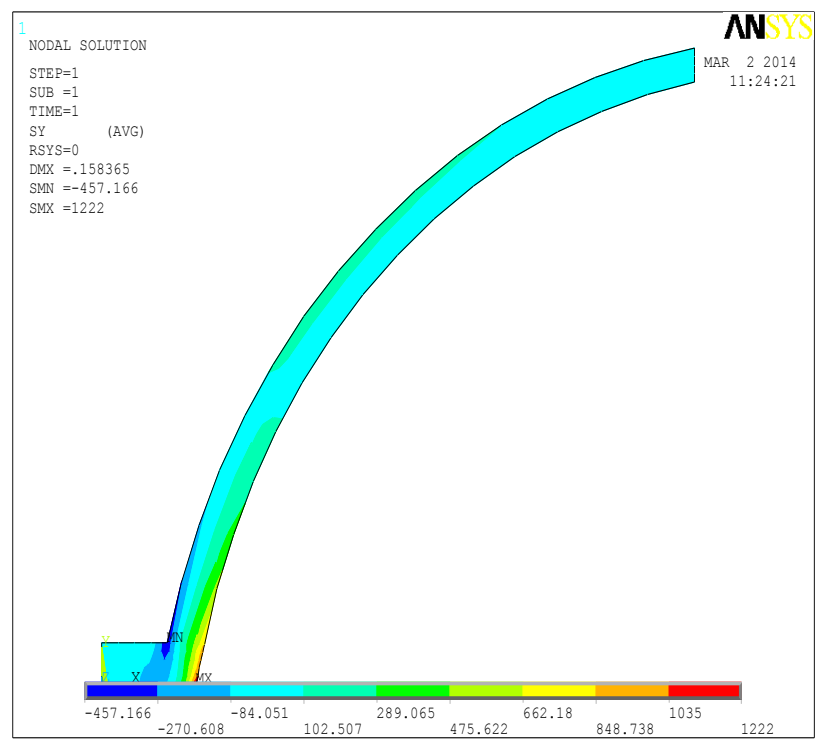

Fig. 10 Stress in y-direction Thermal and mechanical loads

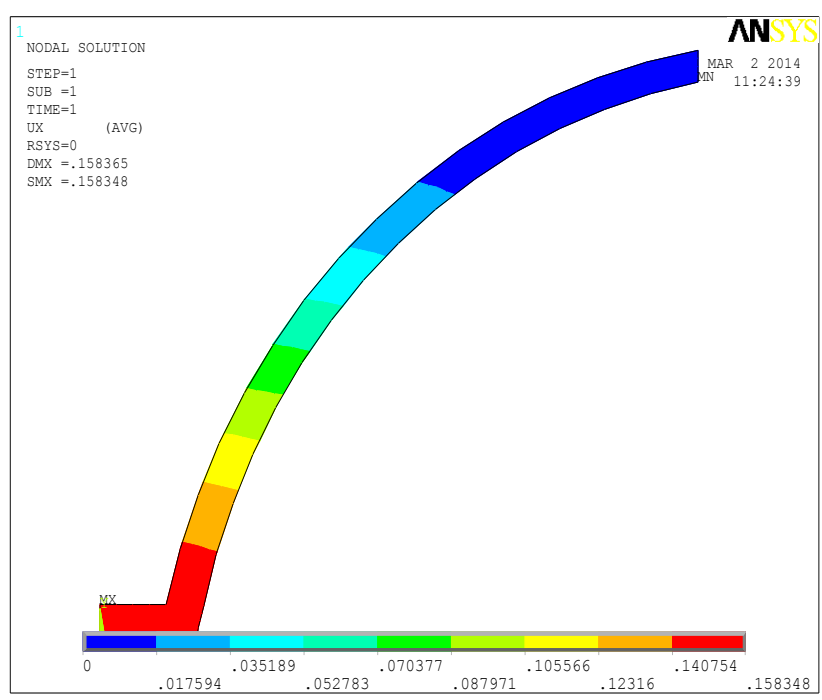

Fig. 11 Displacement in X-direction Thermal and mechanical loads 


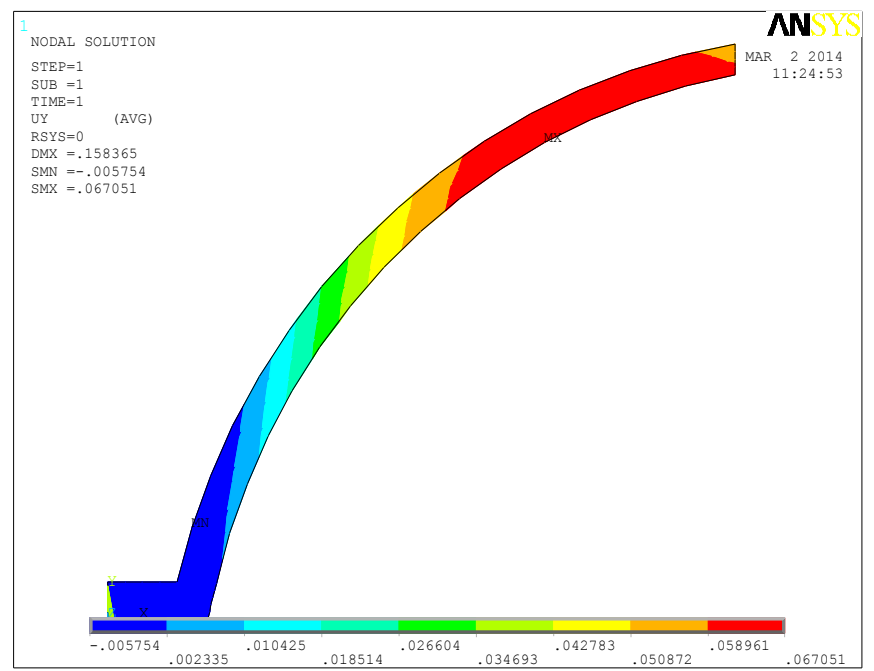

Fig. 12 Displacement in Y-direction Thermal and mechanical loads

\section{Conclusions}

- The present work enabled good insight into the heat transfer and stress aspects of turbine section casing of a $40 \mathrm{MW}$ Gas Turbine. There are moderate stress margins available for allowing minor machining deviations or for increasing the operating parameters (subject to suitability of other components).

\section{References}

[1] Young Jin Choi et al., 2006 Key Engineering Materials (Volumes 306 - 308), 306-308, 169-174.

[2] S. Moaveni, Finite Element Analysis - Theory an Application with ANSYS, Pearson Education, 2008

[2] Fluent 6.3 User's Guide, FLUENT Inc., 2006

[3] Patankar, Suhas v, Numerical heat transfer and Fluid flow. Hemisphere publications, USA.1980.

[4]. H.K.versteeg and W.Malalasekera, An introduction to CFD the Finite volume method, Pearson education limited,2005

[5]. Wallis, G. B., One-Dimensional Two-Phase Flow, McGraw Hill Book Company, New York, 1969.

[6] ASTM A395-99(2014) 